\title{
Urban Planning, Information Technology and Artificial Intelligence: The Theory of Evolution
}

\author{
Anutosh Das ${ }^{a, b}$
}

\author{
a Department of Urban Planning and Design, The University of Hong Kong (HKU), Hong \\ Kong; E-mail: anutosh@hku.hk \\ b Department of Urban \& Regional Planning, Rajshahi University of Engineering \& \\ Technology (RUET), Bangladesh; E-mail: anutosh@urp.ruet.ac.bd
}

Anutosh Das is an Urban Planner by Passion and Profession who wishes to comprehend the interplay between haphazard urban growth and environmental Sustainability of cities from a global, inclusive viewpoint. Mr. Das is a Faculty Member in the Department of Urban \& Regional Planning at Rajshahi University of Engineering \& Technology (RUET), Bangladesh since 2016. He is a graduate in Urban Planning from Bangladesh University of Engineering and Technology (BUET) and currently pursuing MSc. in Urban Planning at the University of Hong Kong (HKU) as an ADB-JSP Fellow. As a professional, he is predominantly interested in effecting positive change in cities and urban environments globally. His research interests are diverse but all revolve around Environmental Planning \& Natural Resource Management focusing Climate Change Adaptation and Natural Resource Economics, Natural Hazard \& Disaster Risk Management, Regional Econometric Analysis and Spatial Planning. His profound academic and professional background focuses on the sound assimilation of the global economic and socio-political context in mainstreaming governance issues as an adaptive measure of global climate change.

Keywords: Urban Planning, Artificial Intelligence, Information Technology, Smart Cities, E-Governance, E-participation and M-participation.

\section{Introduction}

Urban Planning dated back its history since the cities have existed. Early city planning was revolved around some vital elements as buildings and fortification and has undergone a massive transformation throughout the centuries. The $20^{\text {th }}$ century has witnessed several audacious ideas that radically changes the course of conventional urban planning (Routley, 2018).

City planning has always been a challenging and complicated job due to the complex nature of cities as a dynamic living organism. It has never been easy in planning to address diversified city issues holistically in the plan-making process. Nevertheless, in the modern era, the rapid boom of the Information Technology (IT) and Artificial Intelligence (AI) has more significant potential to integrate diversified issues of city planning to a common platform as well as leading to address the challenges of complexity (Hamilton et al., 2005). Meanwhile, the development and advancement of ICT have generated new socio-economic urban activities as well as brought cultural diversities within cities eventually mounting the needs for more flexible and 
change responsive planning intervention. The exponential growth of IT has merged into the urban morphology despite being prominent in appearance. Eventually, a new form of functional space, a virtual environment called "Cyberspace" for urban socio-economic activities have emerged. Growing improvement in information technology and artificial intelligence sector requires cities to integrate the physical and virtual environment in a way to showcase its flexibility to grasp ever-changing complex socio-political interaction happening in the city (Shiode, 2000; Cohen, 2001; Hamilton et al., 2005).

Therefore, this article is an effort to scrutinize the role of Information Technology development in the chronological transformation of Urban Planning domain using the exploratory research approach. In this research, it is argued that the theoretical and practical understanding of Urban Planning should absorb and integrate the bright outcome of the rise of Information and Technology to foster congruent future urban development. The article addresses the trends of transformation in the urban planning domain through the myopic lens of the expansion of information and communications technology era followed by investigating the key drivers shaping the interaction between modern-day urban planning and information technology considering both the dark and bright sides into account.

\section{The Growth of Information Technology and the Evolution of Urban Planning}

The contents and methods of planning change over time from physical and spiritual to multidimensional and more technical. From a historical perspective, planning was primarily concerned with the physical arrangement of activities before the $19^{\text {th }}$ century. However, physical planning and design alone were not sufficient to meet societal needs. Modern town planning in the $20^{\text {th }}$ century has witnessed a paradigm shift in its approach from Idiographic via Positivist to Structuralist approach. The latest trend of urban planning demonstrates an amalgam of Structuralist and Technological Approach since the late 1960s to date (Li, 2019; Yeh, 2020).

Cities are always in the central focus of urban economic activities by nature. A remarkable development in the Information Technology sector has undoubtedly contributed to the propagation of modern-day urban planning. It has been nearly fifty years since IT and AI has been used to assisting our lives as well as the different modes of Urban Planning as a feasible means. But at the beginning of the Information and Communication Technology (ICT) era, the majority of the systems, devices and tools were solely designed to serve specific purposes with minimal effort to collaborate with others. In 1990, the induction of internet and web service boosted notably which fostered the emergence of cyberspace that was visually enhanced. At present, the importance of IT and AI is unavoidable in every aspect of life and it is continually in the grow making urban planning system more efficient day by day (Shiode, 2000; Firmino et al., 2008). The chronological use and integration of ICT \& AI in urban planning is empirically demonstrated in Figure 01. 
Use of ICT \& AI

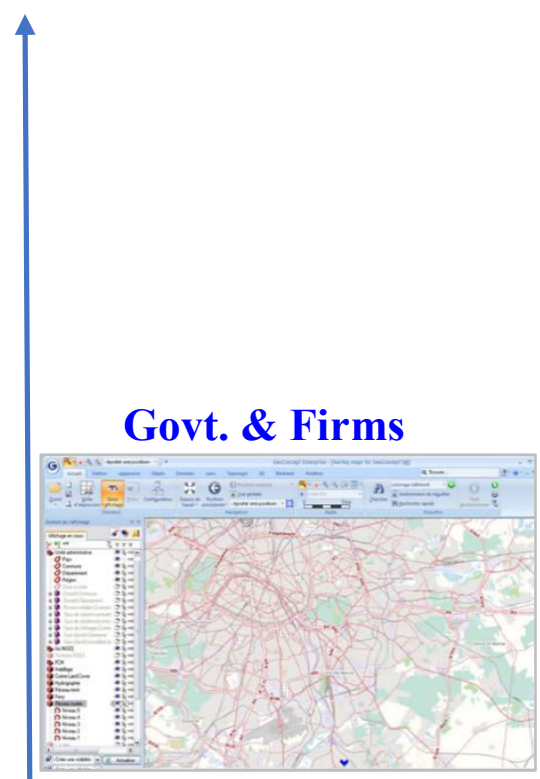

Digital Cities

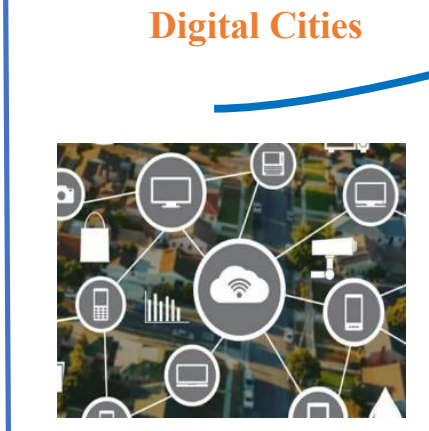

Computers \& LAN
Govt., Firms \& People

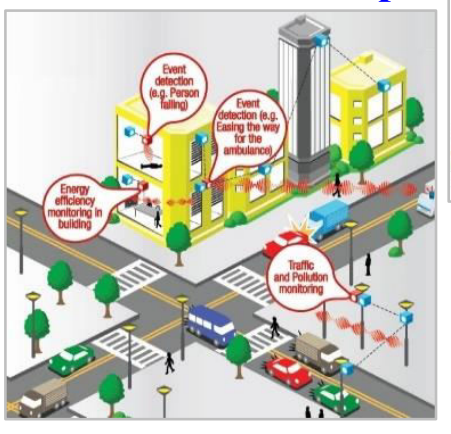

Intelligent Cities

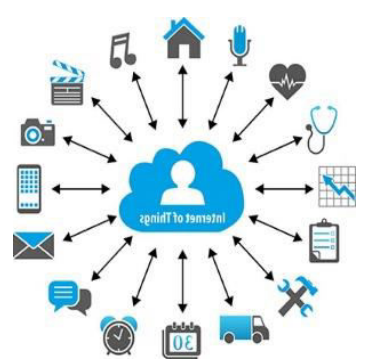

Internet \& Sensors

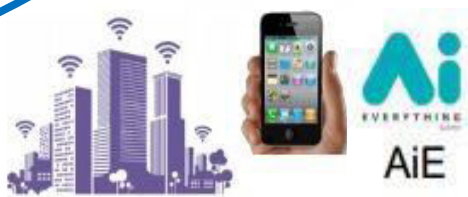

Govt., Firms \& People

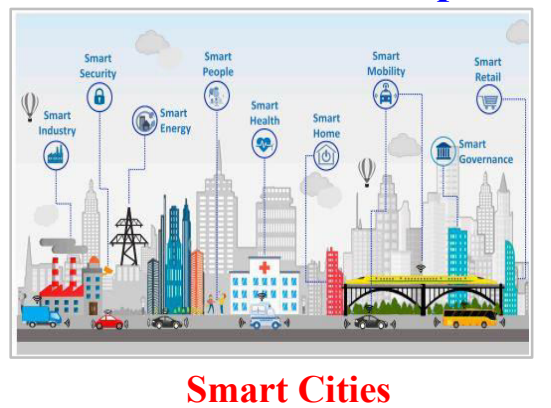

Smart Cities

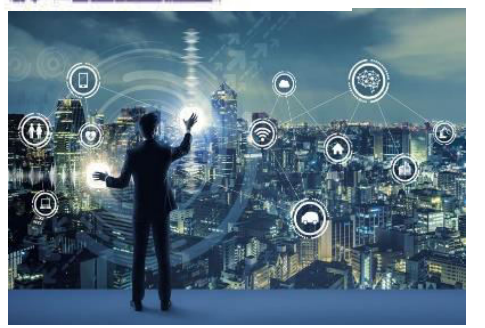

Smart Phones with Wi-Fi, Sensors \& IoT Time 2010- Till Date

Period

1995-2010

Figure 02: Chronological Integration of ICT \& AI in Urban Planning

(Source: Adapted from Yeh, 2020)

Computers have always assisted urban planning and management over the last three decades despite the short history of ICT. Moreover, growing dependency on advanced level IT and AI tools not only complements the contemporary components of cities but also assists in adding another dimension to urban planning for managing socio-economic transformation in the cities with some tools and techniques. The intermingling of physical and electronic space has resulted in "Augmented Space". It has remolded the conventional ways of urban planning i.e. the way we use, control and plans physical spaces in the cities. Augmented Spaces are very crucial to the socio-economic, political and cultural activities (Cohen, 2001). As electronic and physical elements are mutually dependent here, urban planning should seek options to re-think the new mode and instruments to fit in the transformed cities. To Firmino et al. (2008), "This is hard not "just because contemporary cities have reached levels of extreme complexity, but because the notion of 'city' itself is facing a crisis never encountered before".

\section{ICT-Urban Planning Interaction and Core Challenges}

Han \& Kim (1989) have argued that urban information system and artificial intelligence (AI) has focused primarily on providing indispensable information for decision making and more 
intelligent and effective solution to urban problems through integrating data from various sources using emerging and promising technology. The extensive use of the internet results in the emergence of a new urban infrastructure called "Cyberspace' which requires distinguished planning and management concerns. Alongside, with the continuous development of the ICT sector and its intervention in urban Planning, new planning concepts like E-city (electronic city), the ICT city, the information city etc. are on the rise. All these terms highlight the IT and city's interdependent nature. These urban spaces will be mostly driven and governed by the Artificial intelligence and Information Technology sector. The urban policies incorporating ICT in urban planning are widely being recognized as practical tools for sustainable urban management.

Generally, the sound urban environment is a prerequisite for efficient urban development and ICT sector now plays a critical role in this respect to foster environmentally balanced economic growth. Moreover, urban activities are also believed to be primarily affected by the exponential growth of ICT in this modern era. Urban Planners should be aware of this situation about how these changes affect the urban infrastructure and the way to integrate the new ways to planning measures for improving the cyberspace. Most of the social challenges that urban planners face nowadays arise from the intermixing of culture in the highly concentrated cities and new transportation and information network development induced spatial distortion. Modern-day urban planners have also responded to the growing concern by developing and modernizing different supportive tools, i.e. Geographic Information System (GIS), Online-based public participation tools like E-participation and so on. These trendy technologies increase the opportunity for bottom-up participatory planning approach, reduce effort and time for planning activities, handling urban infrastructure and big data etc.

Interlinkage between Information technology and the cities can lead to the classification of contemporary urban space. Figure 02 demonstrates the typical key interactive drivers between these two entities into consideration where both the event-oriented and application side, the infrastructure and facilities management side of urban planning is mostly governed by the ICT sector.

\section{Software}

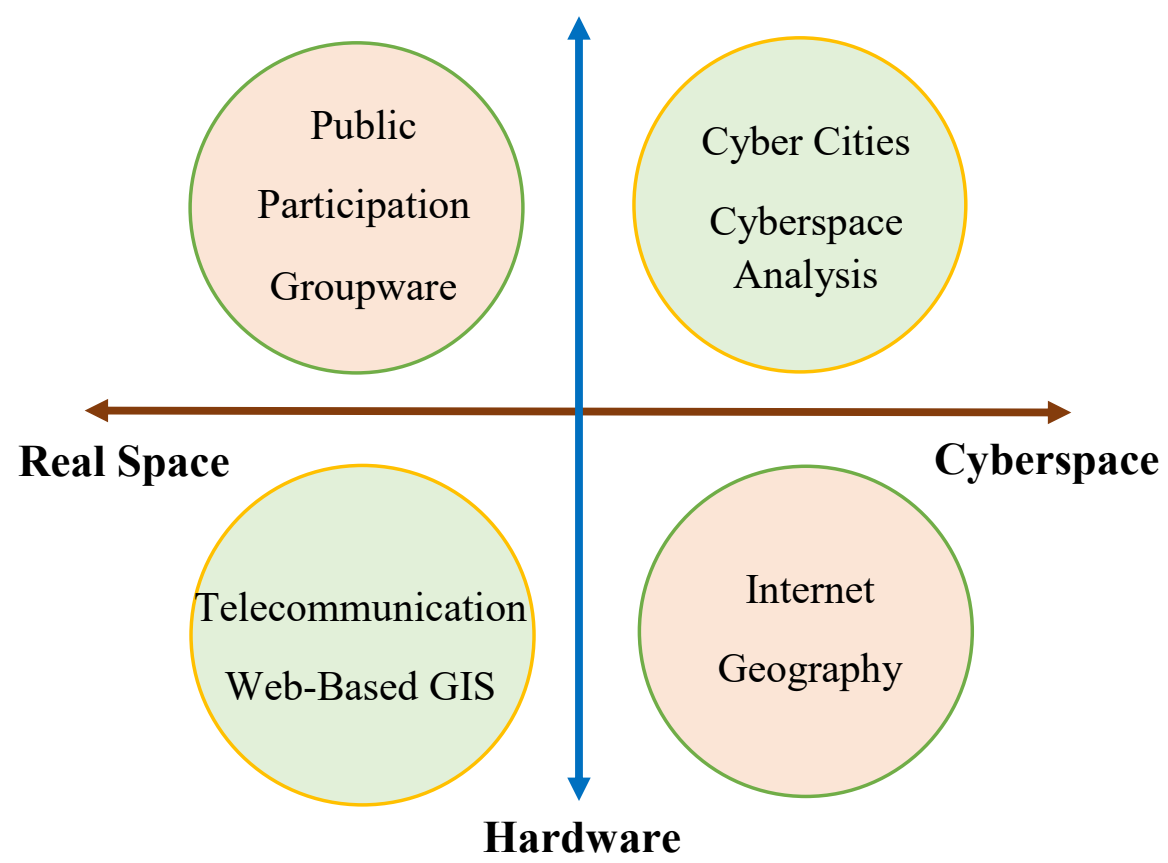

Figure 02: Interaction between Urban Planning and ICT

(Source: Adapted from Shiode, 2000) 


\section{Urban Planning in the ICT Age}

Digitalization of city and development of ICT has modified the conventional notion of urban space and information and hence the urban planners must adapt to this change concentrating the interdependence of IT and urban planning. The rapid boom of communication and transportation networks has improved cross-boundary accessibility beyond the political as well as geographical boundaries of the cities and the nations. Cross-cultural exchange and the suburbanization has resulted in the cities with heterogeneous global culture with changing nature of spatial order. In the age of globalization, the development of ICT is believed to build virtually a single structure through interconnection among the global cities via communication networks. The subsequent sections will highlight the groundbreaking interventions bring into light by the development of ICT and AI sector in the Urban Planning Domain.

\section{Smart Cities: New Sphere of Urban Planning}

In recent times, the concept of "Smart City" is at the crossroad and literally, it is difficult to find any city now without any smart city development initiatives. The future of our cities may be defined more by bytes than bricks in the epoch of big data and urban analytics. Extensive use of Smart Technologies in data collection (i.e. GIS, Sensors, Internet of Things, Big Data), Information processing (e.g. Cloud computing, Machine learning, Data mining) and service provision are the backbones of concurrent smart cities. It has made a paradigm shift in the widespread use of traditional big data source as Census Data, Remote Sensing, Credit Card Data to a more integrated new data source for smart cities like Spatio-Temporal Data, Smart Grid and Sensor Data, Social Network Data for effective decision making (Yeh, 2020).

To be smart, a city should encompass six core areas of intervention as a smart society, smart mobility, smart economy, smart environment, smart life and smart governance (Semiz, 2016; Routley, 2018). It encompasses nearly all of the local government intervention areas in urban planning, i.e. amenities and service provision, solving an energy crisis, urban transportation, democratic transparency and so on. Sensors, Information Technology (IT) and Artificial Intelligence (AI) are at the heart of transformative mechanism of conventional cities becoming smart as demonstrated in Figure 03 (Almirall et al., 2016; Yeh, 2020).

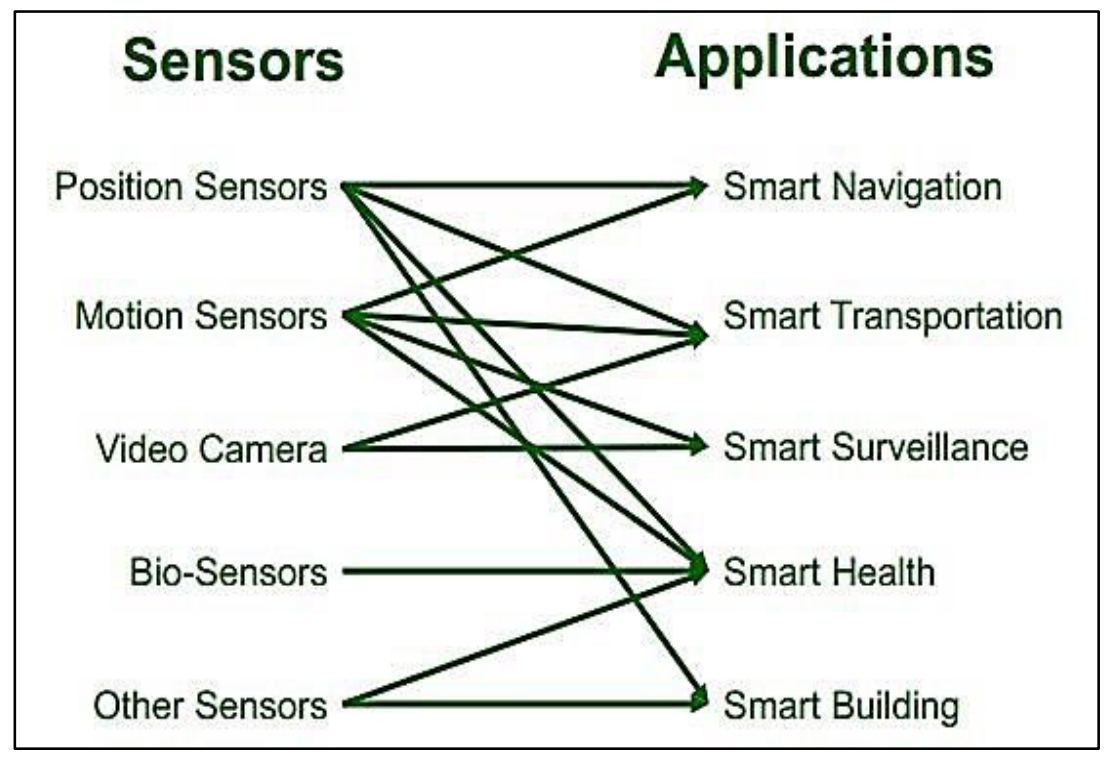

Figure 03: Sensors \& Related IT services in the Heart of Smart Cities (Source: Yeh, 2020) 
Smart city movement is an indicator of more technology-oriented urban planning and sign of efficient use of ICT in city planning and management measures to offer more efficient city administration and better city services. Merely city planning authority now aims only at creating a smart city but also focus on developing futuristic and innovative solutions to contemporary urban problems (Axelsson \& Granath, 2018). Currently, in smart cities, the government is focusing more on disseminating the big data collected from citizen through improved ICT services to ensure the provision of public services in a more sustainable and well-organized manner. A new way of city planning intervention is required to facilitate smart city development initiatives where ICT and AI will be integrated to govern city management function and critical infrastructures (Almirall et al., 2016; Axelsson \& Granath, 2018).

\section{Geographic Information System (GIS) Applications Usage in Urban Planning}

The Geographic Information System (GIS) is a modern tool that is widely used in urban planning through handling geographic location of different areas and services, networking the data and information to the maps which can be updated periodically (Yousef, 2007). It helps urban planners to stimulate rapid data organization, handling and processing big data to prompt the decision-making process for urban development (Aldegheishem \& Alqarni, 2012). It has given another dimension to the urban planning through its contribution in the diversified domain of urban planning e.g. identification of different types of land uses, locational distribution of different amenities and services, providing clarification for the overall vision of the city to meet future urban requirements and other city management functions. It is a very conventional, quick and convenient tool to use for capturing, analyzing, modeling and representing the geo-referenced database in different stages of urban planning (Criado et al., 2019).

Implementing the long-run planning decisions accurate geographic information is of utmost interest in the planning process. Adopting the latest method and techniques, it affects the life and quality of the urban environment directly. Nowadays, urban authorities take advantages of rapid development is GIS technology to develop and provide spatially integrated databases for accurate decision making toward increasing urban development. Consequently, it has become quite impossible to move forward to any urban or socio-economic development without considering the contribution of GIS in Urban Planning (Al-Humaili, 2005).

\section{Online Participatory Tools (E-participation and M-participation)}

The continuous development of ICT and AI has offered a new way of citizen participation in urban planning through online participatory tools (OTPs) as E-participation and Mparticipation. Planning theories always evolves through debate and communication and public participation is a must in the plan-making process (Das, 2020). The wide-ranging use of ICT has facilitated the decision-making process integrating mass public demands and opinions (Healey, 1997; Laurian, 2004; Evans \& Manta, 2006; Hanzl, 2007; Angelidou, 2014; Schweitzer, 2014).

Two distinguished technology predominates online participatory tools (OPTs) e. g. (a) Different web-based tools as Crowdbrite, PlaceSpeak, MySideWalk etc. that are mainly designed for public engagement (b) Social networking sites as Nextdoor, Facebook that can be used for participatory planning centric (Kitchin, 2013; Townsend, 2013; Albino et al. 2015; Fathejalali \& Jain, 2019). OTPs have both its dark (using citizens' mass participation instrumentally, distracting planners and decision-makers from their main goals) and bright side (supporting and facilitating participatory planning processes actively, creating smart cities). In practice, several factors i.e. organizational resources, community characteristics, planners' 
expertise, technology literacy of citizen etc. determine the effectiveness of OPTs in the planning process (Brabham, 2009; Evans \& Hollander, 2010; Mandarano \& Steins, 2010; Belanche et al., 2016; Schweitzer \& Stephenson, 2016; Afzalan \& Evans, 2017).

\section{Democratic E-governance}

E-government is a comparatively new concept in urban planning particularly to assist local planning departments in informing and engaging their citizenry. The development of ICT based e-government tools potentially increase the opportunity for citizen participation in the planmaking process (Healey, 1992; Innes, 1996; Kwan and Weber, 2003). The core focus of this system is to transform the customary file and face oriented jobs to a digital platform. Benefits can be expected from this modernized e-governance in the form of equality of opportunity for the citizen, enhanced efficiency, improved dispersion of public information and so on (Kaylor et al., 2001). The potential and challenge for incorporating e-government tools (i.e. ecommerce) into the plan-making process to urban planners and statutory bodies are both from technical expertise and financial capacities (Conroy \& Evans, 2006; Lee, 2019).

Smart Urban Ecosystems and Combating Climate Change: ICT Based Environmental Decision Making

The world is continually witnessing a breakthrough in technologies and simultaneous population growth and drastic natural resource use as well. The outcome of haphazard human activities has resulted in excessive pressure on the overall carrying capacity of the earth and the resources required to sustain lives. Whereas, the ICT sector only improve the efficiency and performance of urban economies, but also improved numerous tools and techniques to balance environmentally sustainable growth. It offers a new way to engage a community-based environmental decision-making process to support the emergence of a smart urban ecosystem through Visualization and simulation solution for resource conservation, multitude modeling and so on (Yigitcanlar, 2009).

Cities with high population density accompanied by high energy consumption and GHG emission as well contribute largely to the global climate change. In the context of climate change, The ICT and AI are primarily used in the transportation and infrastructure solutions, finding measures to increase energy efficiency in the urban context. ICT supported urban spatial planning and a powerful ecosystem based on information and communication technologies offers an efficient way to use the tools, techniques and methodologies for enabling the adaptation of specific environments to climate change and mitigating the effects of climate change in cities (Marić \& Kovačević, 2016).

\section{Concluding Remark \& Way Forward}

Modern urban planning has a rich and long history dated back from the early $19^{\text {th }}$ century. Meanwhile, the drastic development of information and technologies in the last three decades has brought significant changes in the conventional urban planning process. In some measure, it surpasses the difference in economic condition, regional and cultural context in urban areas. A breakthrough in information technology, as well as improvement in the transportation network, has generated a new form of cities by distorting spatial orders and bringing the distant global cities closer. All these issues have urged for a new framework for urban planning through proper integration of ICT and AI in the planning process. As the city is a very complex and dynamic system with continually changing its characters, socio-economic condition, flexible planning schemes should be adopted for future city planning initiatives with more emphasis on the planning process itself rather than final output that was evident in conventional planning intervention. 


\section{$\underline{\text { References }}$}

Al-Humaili, Y.J (2005), "Realty of Benefitting from Computers in the Public Sector in Saudi Arabia: Obstacles and Solutions", Research Center, Institute of Management, Saudi Arabia, Riyadh.

Aldegheishem, A. J., \& Alqarni, M. (2012), "Assessment of GIS Applications Usage in Urban Planning in Riyadh Region", Arab Gulf Journal of Scientific Research, 30(1), pp. 2332,http://eproxy.lib.hku.hk/login?url=http://search.ebscohost.com/login.aspx?direct=tr $\mathrm{ue} \& \mathrm{db}=$ obo $\& A N=85810402 \&$ site $=$ ehost-live $\&$ scope $=$ site $($ last accessed on 10 May 2020).

Angelidou, M. (2014), “Smart city policies: A spatial approach” Cities, 41, pp. S3-S11.

Albino, V., Berardi, U., \& Dangelico, R. M. (2015), "Smart cities: Definitions, dimensions, performance, and initiatives", Journal of Urban Technology, 22(1), pp. 3-21.

Almirall, E., Wareham, J., Ratti, C., Conesa, P., Bria, F., Gaviria, A., \& Edmondson, A. (2016), "Smart Cities at the Crossroads: NEW TENSIONS IN CITY TRANSFORMATION" California Management Review, 59(1), pp. 141-152. doi:10.1177/000812561668394

Afzalan, N., Sanchez, T. W., \& Evans-Cowley, J. (2017), "Creating smarter cities: Considerations for selecting online participatory tools", Cities, 67, pp. 21-30. doi:https://doi.org/10.1016/j.cities.2017.04.002

Axelsson, K., \& Granath, M. (2018), “Stakeholders' stake and relation to smartness in smart city development: Insights from a Swedish city planning project" Government Information Quarterly, 35(4), 693-702. doi:10.1016/j.giq.2018.09.001

Brabham, D. C. (2009), "Crowdsourcing the public participation process for planning projects”, Planning Theory, 8(3), pp. 242-262.

Belanche, D., Casaló, L. V., \& Orús, C. (2016), “City attachment and use of urban services: Benefits for smart cities", Cities, 50, pp. 75-81.

Cohen, G. (2001). "Urban Planning and Information and Communication Technology", Paper presented at the Tinbergen Institute Discussion Paper, Burg. Oudlaan 50,The Netherlands.

Conroy, M. M., \& Evans-Cowley, J. (2006), "E-participation in planning: an analysis of cities adopting on-line citizen participation tools", Environment \& Planning C: Government \& Policy, 24(3), pp. 371-384. doi:10.1068/c1k

Criado, M., Martínez-Graña, A., Santos-Francés, F., \& Veleda, S. (2019), “ INTEGRATION OF GIS TECHNOLOGY IN THE URBAN PLANNING TO EXTEND THE CITY OF ZAMORA, SPAIN", Environmental Engineering \& Management Journal (EEMJ), 18(7), pp. 1399-1409, http://eproxy.lib.hku.hk/login?url=http://search. ebscohost.com/ login. asp ?direct $=$ true $\& \mathrm{db}=8 \mathrm{gh} \& \mathrm{AN}=137957522 \&$ site $=$ ehost-live $\&$ scope $=$ site, (last accessed on 14 May 2020).

Das, A. (2020), "Bridging the Urban Divide: A Critical Review of Bottom-Up Communicative Planning Measures in Bangladesh", International Journal of Town Planning and Management, 6(1), pp. 1-10.

Evans-Cowley, J. (2010), "Planning in the Real-Time City: The Future of Mobile Technology" Journal of Planning Literature, 25(2), pp. 136-149. 
Evans-Cowley, J., \& Hollander, J. (2010), "The new generation of public participation: Internet-based participation tools", Planning Practice and Research, 25(3), pp. 397408.

Firmino, R., Duarte, F., \& Moreira, T. (2008), "Pervasive Technologies and Urban Planning in the Augmented City", Journal of Urban Technology, 15(2), pp. 77-93. doi:10.1080/10630730802401983

Fathejalali, A., \& Jain, A. (2019), "Mobile participation (mParticipation) in urban development: The experience of FlashPoll app in Berlin (Germany)" Information Polity: The International Journal of Government \& Democracy in the Information Age, 24(2), 199-222. doi:10.3233/IP-180096

Han, S. \& Kim, T. (1989), “Can Expert Systems Help with Planning?”, Journal of the American Planning Association, 55(3), pp. 296-308. DOI: 10.1080/01944368908975417

Healey P. (1992), "Planning through debate: the communicative turn in planning theory", Town Planning Review, 63, pp. 143-162.

Hamilton, A., Wang, H., Tanyer, A. M., Arayici, Y., Zhang, X., \& Song, Y. (2005), "Urban information model for city planning" Journal of Information Technology in Construction (ITCon), 10(6), pp. 55-67.

Hanzl, M. (2007), "Information technology as a tool for public participation in urban planning: a review of experiments and potentials", Design Studies, 28(3), pp. 289-307.

Innes J E. (1996), "Planning through consensus building", Journal of the American Planning Association, Autumn, 62, pp. 460-472.

Kaylor C, Deshazo R,Van Eck D. (2001), "Gauging e-government: a report on implementing services among American cities”, Government Information Quarterly, 18, pp. 293-307.

Kwan M P,Weber J. (2003), “Individual accessibility revisited: implications for geographical analysis in the twenty-first century", Geographical Analysis, 35, 341-353.

Kitchin, R. (2013), "The real-time city? Big data and smart urbanism", GeoJournal, 79(1), pp. 1-14. http://dx.doi.org/10.1007/s10708-013-9516-8.

Laurian, L. (2004), "Public Participation in Environmental Decision Making: Findings from Communities Facing Toxic Waste Cleanup", Journal of the American Planning Association, 70(1), pp. 53-65.

Lee-Geiller, S., \& Lee, T. (2019), "Using government websites to enhance democratic Egovernance: A conceptual model for evaluation", Government Information Quarterly, 36(2), pp. 208-225. doi:10.1016/j.giq.2019.01.003

Li, W. (2019), "History of Urban Planning”, Lecture Series, Values in Planning, M.Sc. (Urban Planning) Program, The University of Hong Kong.

Mandarano, L., Meenar, M., \& Steins, C. (2010), "Building social capital in the digital age of civic engagement", Journal of Planning Literature, 25(2), pp. 123-135.

Marić, I., Pucar, M., \& Kovačević, B. (2016), "Reducing the impact of climate change by applying information technologies and measures for improving energy efficiency in urban planning" Energy \& Buildings, 115, 102-111. doi:10.1016/j.enbuild.2015.04.044 
Routley, N. (2018), “The Evolution of Urban Planning”, Visual Capitalist, https://www. visualcapitalist.com/evolution-urban-planning/, (last accessed on 09 April 2020).

Shiode, N. (2000), "Urban Planning, Information Technology, and Cyberspace”, Journal of Urban Technology, 7(2), pp. 105-126. doi:10.1080/713684111

Schweitzer, L. (2014) "Planning and social media: A case study of public transit and stigma on twitter",Journal of the American Planning Association, 80(3), pp. 218-238. http://dx.doi.org/10.1080/01944363.2014.980439.

Semiz, T. (2016), “Technological Solutions for The Future of Cities: Turkcell Smart City Gaziantep Case", Proceedings of the Multidisciplinary Academic Conference, 104109,http://eproxy.lib.hku.hk/login?url=http://search.ebscohost.com/login.aspx?direct= true $\& \mathrm{db}=\mathrm{a} 9 \mathrm{~h} \& \mathrm{AN}=115706672 \&$ site $=$ ehost-live $\&$ scope $=$ site (last accessed on 08 May 2020).

Townsend, A. (2013), Smart cities: Big data, civic hackers, and the quest for a new utopia, NY: WW Norton \&Company.

Yousef, W.M. (2007), “The Role of Municipalities in the Development of Electronic City", Al-Azhar Engineering Conference IX, Faculty of Engineering, Al-Azhar University, Cairo, Arab Republic of Egypt.

Yigitcanlar, T. (2009), "Planning For Smart Urban Ecosystems: Information Technology Applications For Capacity Building In Environmental Decision Making", Theoretical \& Empirical Researches in Urban Management, 3(12), pp. 5-21, http://eproxy.lib.hku.hk/login?url=http://search.ebscohost.com/ login.aspx?direct= true $\& \mathrm{db}=$ obo \&AN $=59336818 \&$ site $=$ ehost-live $\&$ scope $=$ site, $($ last accessed on 08 May 2020).

Yeh, A. (2020), "Introduction to Urban Modeling and Planning Support System", Lecture Series, Research Methods in Spatial Planning, M.Sc. (Urban Planning) Program, The University of Hong Kong. 